\title{
Prevalence of physical inactivity and associated factors among high school students from state's public schools
}

\author{
Fabio L. Ceschini, ${ }^{1}$ Douglas R. Andrade, ${ }^{2}$ Luis C. Oliveira, ${ }^{3}$ \\ Jorge F. Araújo Júnior, ${ }^{4}$ Victor K. R. Matsudo ${ }^{5}$
}

\begin{abstract}
Objective: To describe the prevalence of physical inactivity and associated factors among high school students from state's public schools in the city of São Paulo, state of São Paulo, Brazil.

Methods: Sixteen state's public schools were randomly selected according to the geographic areas of the city (North, South, East, and West). The sample consisted of 3,845 high school students in 2006. Physical inactivity was measured using the International Physical Activity Questionnaire (short IPAQ) and was defined as practicing moderate and/or vigorous physical activity for a period of less than 300 minutes per week. The independent variables analyzed were: gender, age, socioeconomic level, geographic area of the city, awareness of the "Agita São Paulo" program, participation in physical education classes, smoking, alcohol intake and time spent per day watching television. Threelevel Poisson regression was used for assessing the variables, with a significance level of $p<0.05$.

Results: The general prevalence of physical inactivity among adolescents in São Paulo was $62.5 \%$ (95\%CI 60.5-64.1). The factors associated with physical inactivity were gender, age, socioeconomic level, geographic area of the city, awareness of the "Agita São Paulo" program, non-participation in physical education classes, smoking, alcohol intake and time spent per day watching television.

Conclusion: It was concluded that the prevalence of physical inactivity among adolescents in São Paulo was high in all the geographic areas evaluated, and that sociodemographic and behavioral factors contributed significantly to physical inactivity.
\end{abstract}

J Pediatr (Rio J). 2009;85(4):301-306: Adolescence, physical activity, health promotion.

\section{Introduction}

The benefits provided by the regular practice of physical activity during childhood and adolescence are important for the biological process of human growth and development because they enable improvement of cardiovascular, metabolic, skeletal muscle functions and assist with the control and reduction of body fat. ${ }^{1}$
Scientific evidence has demonstrated that chronic degenerative diseases such as type 2 diabetes, cardiovascular diseases, osteoporosis, among others, have their onset during childhood and adolescence and may be potentiated depending on the individual's life style, mainly when there are bad eating habits and physical inactivity. ${ }^{2}$ Therefore,

1. Mestre, Saúde Pública, Departamento de Nutrição, Faculdade de Saúde Pública, Universidade de São Paulo (USP), São Paulo, SP, Brazil.

2. Mestre, Saúde Pública, Faculdade de Saúde Pública, USP, São Paulo, SP, Brazil.

3. Mestre, Promoção da Saúde, Universidade São Judas Tadeu (USJT), São Paulo, SP, Brazil.

4. Mestre, Adaptação Humana, Universidade do Vale do Paraíba (UNIVAP), São José dos Campos, SP, Brazil.

5. Livre-docente, Universidade Gama Filho (UGF), Rio de Janeiro, RJ, Brazil.

No conflicts of interest declared concerning the publication of this article.

Suggested citation: Ceschini FL, Andrade DR, Oliveira LC, Araújo Júnior JF, Matsudo VK. Prevalence of physical inactivity and associated factors among high school students from state's public schools. J Pediatr (Rio J). 2009;85(4):301-306.

Manuscript submitted Dec 19 2008, accepted for publication May 182009.

doi:10.2223/JPED.1915 
the regular practice of physical activity is an important behavior to prevent chronic diseases and it must be promoted during the whole growth and development process so that such behavior become more likely to become a habit in adulthood as has been demonstrated by international ${ }^{3,4}$ and Brazilian studies. ${ }^{5}$

Adolescents should engage in moderate to vigorous physical activities for at least 60 minutes a day, thus reaching 300 minutes a week. Such activities may be practiced at school or not, either consisting of supervised or unsupervised practice. ${ }^{1}$ However, international studies have found high prevalence of physical inactivity among Finnish, ${ }^{6}$ American, ${ }^{7}$ and Portuguese ${ }^{8}$ adolescents. A similar trend was found in studies involving Brazilian youths from the cities of Pelotas, state of Rio Grande do Sul, ${ }^{9}$ and São Paulo, state of São Paulo. ${ }^{10}$ Thus, quantification of the prevalence of physical inactivity and identification of risk groups are important to define the focus of intervention strategies.

Only two studies have established the prevalence of physical inactivity and possible associated factors among adolescents from the city of São Paulo, and these studies have involved only regional populations, such as adolescents from some private schools located in the South area of the city ${ }^{11}$ or adolescents from only one public school located in the North area of the city. ${ }^{10}$ Therefore, there is a gap in our knowledge about the prevalence of physical inactivity among adolescents considering the different areas in the city of São Paulo (North, South, East and West).

Hence, the objective of this study was to describe the prevalence of physical inactivity and associated factors among high school students from state's public schools in the city of São Paulo, Brazil.

\section{Methods}

São Paulo is the third biggest city in the world and has the 19th highest GDP in the world. It has approximately 11 million inhabitants, and 1 million of them are adolescents aged between 14 and 19 years old. ${ }^{12}$

Of the 703 state's public schools that provided high school education in the mornings in the city of São Paulo in 2006, $29.4 \%$ were located in the South area, $30.1 \%$ were in the East area, 20.5\% were in the West area, and $20.0 \%$ were in the North area. Schools were stratified according to the geographic areas in the city of São Paulo (North, South, East or West). Next, four schools were randomly selected in each area, totalizing 16 schools selected for the study. The percentage value of the number of schools assessed for the total number of schools in each area was: $2.0 \%$ of schools assessed were located in the South area, $1.9 \%$ was located in the East area, $2.7 \%$ were in the West area and $2.8 \%$ were in the North area. Schools had from six to eight groups of high school students in the mornings. Then, five groups from each school were selected. All students from each group were included in the sample, which consisted of 3,845 students, whose mean age was 15.3 years.

Socioeconomic level was assessed using the questionnaire of socioeconomic classification of the Brazilian Association of Survey Companies (Associação Brasileira de Empresas de Pesquisa), which takes into consideration the educational level of the head of the household and some consumer goods, and the socioeconomic classification is divided into five levels from A to E. ${ }^{13}$

The International Physical Activity Questionnaire (IPAQ), short version 8 , was used to collect information on the dependent variable (physical inactivity). The IPAQ was initially developed by a group of international researchers in 1998 with the purpose of validating a single instrument that would enable a worldwide survey on the prevalence of physical activity/inactivity in adults. Twelve research centers selected from all around the world came together to design the questionnaire, and our center (Centro de Estudos do Laboratório de Aptidão Física de São Caetano do Sul, CELAFISCS) was in charge of the task in Brazil.14 The IPAQ was also validated for Brazilian adolescents ${ }^{15}$ and has been used to assess the level of physical activity in this group. 11,16

Physical inactivity was defined as the practice of vigorous and/or moderate physical activities at school or not, either consisting of supervised or unsupervised practice, for less than 300 minutes a week, in accordance with the guidelines of physical activities for adolescents. ${ }^{1}$

Adolescents' life style, considering smoking, alcohol intake and time spent per day watching television, was assessed using part of the Questionnaire of Assessment of Health Status, Nutrition and Physical Activity. ${ }^{17}$ The adolescents who reported smoking at least once a week were classified as smokers. Any intake of alcoholic beverage at least once a month before the assessment was taken into consideration. The independent variables were gender (boys or girls), age group (14-16 or 17-19 years old), socioeconomic level (A, B, C, D or E), area of the city (North, South, East or West), awareness of the program of physical activity promotion "Agita São Paulo" (is aware of it or not), participation in physical education classes (participates or does not participate), smoking (yes or no), alcohol intake (yes or no) and time spent per day watching television (< $1 \mathrm{~h} /$ day, from 1 to $2 \mathrm{~h} /$ day or $>2 \mathrm{~h} /$ day).

Data collection was performed between February and April 2006 by four physical education teachers. The questionnaires were completed by the adolescents. Participation in the study was authorized by parents or guardians who signed a written consent form, which guaranteed anonymity.

Prevalence of physical inactivity was calculated for the categories of each independent variable. The significance level between the proportions was assessed using the 
chi-square test for heterogeneity or for linear trend. In the multivariate analysis, Poisson regression was used to estimate the prevalence ratios (PR) and their respective confidence intervals $(95 \% \mathrm{CI})$. The order the variables were entered followed the hierarchical causal model determined a priori. ${ }^{18}$

This is a three-level model. In order to make sure that the independent variable remains in the adjusted model, it should have a significance level of $p<0.20$ in the crude analysis. Sociodemographic variables were entered in the first level (gender, age, socioeconomic level and geographic area of the city of São Paulo). Those variables related to the promotion of physical activity practice (awareness of the program "Agita São Paulo" and participation in physical education classes) were entered in the second level, and the adolescents' behavioral variables (smoking, alcohol intake and time spent per day watching television) were entered in the third level. Significance level was set at $p<0.05$.

\section{Results}

Sociodemographic characteristics, those characteristics related to the promotion of physical activity practice and behavioral characteristics are shown in Table 1. Half of the adolescents reported they did not participate in physical education classes, and girls constituted the most prevalent group (78.2\%). Smoking prevalence was 35.6\%, being significantly higher in boys $(67.5 \%)$ in comparison to girls $(32.5 \%), p=0.036$. With regard to the intake of alcoholic

Table 1 - Sociodemographic and behavioral characteristics of high school students from state's public schools (São Paulo, SP, Brazil, 2006)

\begin{tabular}{|c|c|c|}
\hline Sociodemographic characteristics & $\mathbf{n}$ & $\%$ \\
\hline \multicolumn{3}{|l|}{ Gender } \\
\hline Male & 1,824 & 47.4 \\
\hline Female & 2,021 & 52.6 \\
\hline \multicolumn{3}{|l|}{ Age } \\
\hline $14-16$ years & 2,430 & 63.2 \\
\hline $17-19$ years & 1,415 & 36.8 \\
\hline \multicolumn{3}{|l|}{ Socioeconomic level } \\
\hline A & 68 & 1.8 \\
\hline B & 92 & 2.4 \\
\hline $\mathrm{C}$ & 1,178 & 30.6 \\
\hline $\mathrm{D}$ & 1,093 & 28.4 \\
\hline$E$ & 1,414 & 36.8 \\
\hline \multicolumn{3}{|l|}{ Geographic area of São Paulo } \\
\hline South & 932 & 24.2 \\
\hline East & 1,025 & 26.6 \\
\hline North & 944 & 24.6 \\
\hline West & 944 & 24.6 \\
\hline \multicolumn{3}{|l|}{ Program "Agita São Paulo" } \\
\hline Is aware of it & 2,766 & 71.9 \\
\hline Is not aware of it & 1,079 & 28.1 \\
\hline \multicolumn{3}{|l|}{ Physical education } \\
\hline Participates & 1,903 & 49.5 \\
\hline Does not participate & 1,942 & 50.5 \\
\hline \multicolumn{3}{|l|}{ Smoking } \\
\hline No & 2,476 & 64.4 \\
\hline Yes & 1,369 & 35.6 \\
\hline \multicolumn{3}{|l|}{ Alcohol intake } \\
\hline No & 1,830 & 47.6 \\
\hline Yes & 2,015 & 52.4 \\
\hline \multicolumn{3}{|l|}{ Time spent watching TV per day } \\
\hline$<1 \mathrm{~h} /$ day & 1,377 & 35.8 \\
\hline From 1 to $2 \mathrm{~h} /$ day & 1,350 & 35.1 \\
\hline$>2$ h/day & 1,118 & 29.1 \\
\hline Total & 3,845 & 100.0 \\
\hline
\end{tabular}


beverages, the prevalence was $52.4 \%$, and there was no statistical difference between boys (55.6\%) and girls $(47.6 \%), p=0.178$.

The general prevalence of physical inactivity among high school students from state's public schools in São Paulo was $62.5 \%$ (95\%CI 60.5-64.1). Among the adolescents who followed the recommendation of practicing physical activity, $47 \%$ practiced supervised physical activities at health clubs managed by the city administration. The results shown in Table 2 demonstrated that the prevalence of physical inactivity was significantly higher for girls $(74.1 \%)$, the oldest age group (71.6\%), socioeconomic level B (88\%), and adolescents from schools located in the West area of São Paulo (83.9\%).

Prevalence of physical inactivity was significantly higher for adolescents who were not aware of the program "Agita São Paulo" (75.6\%), for students who did not participate in the physical education classes regularly $(61.6 \%)$, and for

Table 2 - Crude and adjusted prevalence ratios of physical inactivity according to the categories of independent variables for high school students from state's public schools (São Paulo, SP, Brazil, 2006)

\begin{tabular}{|c|c|c|c|c|c|}
\hline \multirow[b]{2}{*}{ Variables } & \multirow[b]{2}{*}{$\begin{array}{c}\text { PI prevalence } \\
\text { n }(\%)\end{array}$} & \multicolumn{4}{|c|}{ Multivariate analysis } \\
\hline & & $\begin{array}{c}\text { Crude PR } \\
(95 \% \mathrm{CI})\end{array}$ & $\mathbf{p}$ & $\begin{array}{c}\text { Adjusted PR } \\
(95 \% \mathrm{CI})\end{array}$ & $\mathbf{p}$ \\
\hline Gender & & & $<0.001^{*}$ & & $<0.001^{*}$ \\
\hline Male & $907(49.7)^{\dagger}$ & 1.00 & & 1.00 & \\
\hline Female & $1,498(74.1)$ & $1.49(1.37-1.62)$ & & $1.48(1.37-1.63)$ & \\
\hline Age & & & $0.022^{*}$ & & $0.035^{*}$ \\
\hline $14-16$ years & $1,492(61.4)^{\dagger}$ & 1.00 & & 1.00 & \\
\hline 17-19 years & $1,013(71.6)$ & $1.17(1.07-1.29)$ & & $1.09(1.02-1.38)$ & \\
\hline Socioeconomic level & & & $<0.001^{\ddagger}$ & & $0.004^{\ddagger}$ \\
\hline A & $51(75.0)^{\S}$ & $1.38(1.04-1.83)$ & & $1.34(1.02-1.79)$ & \\
\hline $\mathrm{B}$ & $81(88.0)$ & $1.62(1.29-2.04)$ & & $1.58(1.24-1.94)$ & \\
\hline $\mathrm{C}$ & $777(66.0)$ & $1.21(1.10-1.34)$ & & $1.15(1.06-1.29)$ & \\
\hline $\mathrm{D}$ & $729(66.7)$ & $1.23(1.11-1.36)$ & & $1.14(1.04-1.30)$ & \\
\hline$E$ & $767(54.2)$ & 1.00 & & 1.00 & \\
\hline Geographic area & & & $<0.001^{\ddagger}$ & & $<0.001^{\ddagger}$ \\
\hline South & $417(44.7)^{\S}$ & 1.00 & & 1.00 & \\
\hline East & $703(68.6)$ & $1.53(1.38-1.70)$ & & $1.43(1.29-1.62)$ & \\
\hline North & $693(73.4)$ & $1.64(1.52-1.77)$ & & $1.55(1.41-1.70)$ & \\
\hline West & $792(83.9)$ & $1.87(1.73-2.01)$ & & $1.78(1.64-1.86)$ & \\
\hline Program "Agita São Paulo" & & & $<0.001^{*}$ & & $<0.001^{*}$ \\
\hline Is aware of it & $1,589(54.7)^{\dagger}$ & 1.00 & & 1.00 & \\
\hline Is not aware of it & $816(75.6)$ & $1.32(1.21-1.43)$ & & $1.29(1.16-1.38)$ & \\
\hline Physical education & & & $<0.001^{*}$ & & $<0.001^{*}$ \\
\hline Participates & $832(42.8)^{+}$ & 1.00 & & 1.00 & \\
\hline Does not participate & $1,173(61.6)$ & $1.44(1.32-1.57)$ & & $1.39(1.29-1.53)$ & \\
\hline Smoking & & & $<0.001^{*}$ & & $<0.001^{*}$ \\
\hline No & $1,112(44.9)^{\dagger}$ & 1.00 & & 1.00 & \\
\hline Yes & $1,293(94.7)$ & $2.11(1.32-2.89)$ & & $2.06(1.31-2.82)$ & \\
\hline Alcohol intake & & & $<0.001^{*}$ & & $<0.001^{*}$ \\
\hline No & $770(42.1)^{\dagger}$ & 1.00 & & 1.00 & \\
\hline Yes & $1,635(81.3)$ & $1.93(1.21-2.78)$ & & $1.86(1.17-2.72)$ & \\
\hline Time spent watching TV per day & & & $<0.001^{\ddagger}$ & & $<0.001^{\ddagger}$ \\
\hline$<1 \mathrm{~h} /$ day & $673(48.9)^{\S}$ & 1.00 & & 1.00 & \\
\hline From 1 to $2 \mathrm{~h} /$ day & $785(58.1)$ & $1.19(1.07-1.32)$ & & $1.17(1.04-1.30)$ & \\
\hline$>2 \mathrm{~h} /$ day & $947(84.7)$ & $1.73(1.57-1.91)$ & & $1.54(1.38-1.72)$ & \\
\hline Total & $2,405(62.5)$ & & & & \\
\hline
\end{tabular}

$95 \% \mathrm{Cl}=95 \%$ confidence interval; $\mathrm{PI}=$ physical inactivity; $\mathrm{PR}=$ prevalence ratio.

* Wald test for heterogeneity.

† Chi-square test for heterogeneity.

₹ Wald test for linear trend.

$\S$ Chi-square test for linear trend. 
those who watched TV for longer than 2 hours (84.7\%). Adolescents who smoked (94.7\%) and drank alcoholic beverages $(81.3 \%)$ were significantly more inactive.

The results of the hierarchical multivariate analysis showed that the independent variables that were significant in the crude analysis had a similar behavior after the adjusted analysis. In the adjusted model, girls were $48 \%$ $(P R=1.48 ; 95 \% C I 1.37-1.63)$ more inactive than boys. Students from schools located in the West area of the city were $87 \%(P R=1.78 ; 95 \% C I 1.64-1.86)$ more inactive if compared to adolescents from the South area. Not being aware of the program "Agita São Paulo" increased the probability of being inactive for $29 \%$ ( $P R=1.29 ; 95 \% C I$ 1.16-1.38) in comparison with those who reported being aware of the program.

Regarding the adolescents' behavioral variables, even after adjusting for the variables belonging to the higher levels, we found that the length of time spent watching TV was positively associated with physical inactivity, and the risk effect was higher for the group that watched more than 2 hours a day. However, none of the independent variables assessed presented higher probability of physical inactivity than smoking ( $P R=2.06 ; 95 \% C I 1.31-2.82$ ) and alcohol intake ( $P R=1.86 ; 95 \% C I$ 1.17-2.72).

\section{Discussion}

International6,8,19 and Brazilian ${ }^{9-11}$ studies have demonstrated that girls have a higher probability of being inactive. A similar trend was found in the present study, with girls being $48 \%$ more inactive than boys.

Adolescents from schools located in the West and North areas of São Paulo were significantly more inactive. These results could be explained by the number of public sports facilities available for the population in each area of the city. Of the 331 public sports facilities available in the city, $48(14.7 \%)$ and $57(17.5 \%)$ are located in the West and North areas, respectively. ${ }^{20}$ Therefore, the smaller number of public sports facilities in these areas could be contributing to the higher prevalence of physical inactivity in youths, since $47 \%$ of the adolescents reported the practice of physical activities at health clubs managed by the city administration. ${ }^{21}$

Adolescents classified at the A and B levels were significantly more inactive. These results are important, since some studies have shown similar results, 9,10 and other studies have found different results, probably due to different physical, social and environmental characteristics of each population, according to what has been discussed in a recent literature review. ${ }^{22}$

On the other hand, secondary results regarding the objective of the present study should be commented. Prevalence of smoking and alcohol intake among adolescents from São Paulo was higher than the data found in other Brazilian studies; for instance, among adolescents from Florianópolis, state of Santa Catarina, ${ }^{23}$ and Porto Alegre, state of Rio Grande do Sul. ${ }^{24}$ Therefore, intervention programs are necessary to stimulate the daily practice of physical activities, as well as to reduce smoking and alcohol intake among high school students from São Paulo.

Regarding the promotion of physical activity, the multivariate analysis demonstrated that not being aware of the program "Agita São Paulo" was associated with physical inactivity. In a recent study, the authors found that the proportion of physical inactivity was 12 times higher among adolescents from schools where no activity of the program "Agita São Paulo" was conducted in comparison to those adolescents from schools where the event took place (no program: $19.9 \%$; program: $1.6 \%$ ), suggesting that such events, as well as the participation of adolescents, could have an influence on the level of physical activity. ${ }^{25}$

The engagement of adolescents in supervised or non-supervised physical activities has an inverse relation to smoking and alcohol intake. The study by Nelson \& Gordon-Larsen ${ }^{26}$ investigated the association between physical activity and risk behaviors among 11,957 American adolescents. Practicing physical activity at school $(P R=0.82 ; 95 \% C I 0.71-0.95)$ and at recreational centers $(P R=0.80 ; 95 \% C I 0.69-0.92)$ and practicing sports $(P R=0.61 ; 95 \% C I 0.54-0.69)$ were protective factors against smoking. In terms of alcohol consumption, data demonstrated that practicing moderate physical activities 5 or more days a week was a protective factor against alcohol intake (PR $=0.84 ; 95 \%$ CI 0.74-0.96).

Therefore, the results presented in our study and current scientific evidence suggest that the engagement of adolescents in physical activities stimulated by health promotion programs at school or not could contribute to the reduction of physical inactivity, probably because it raises awareness of the importance and benefits for health and also due to the greater involvement of adolescents in these activities. In that sense, the action of schools and governmental agencies seems to be an interesting manner to create and implement intervention programs that assist to prevent physical inactivity, smoking and alcohol intake. ${ }^{27}$

In the present study, only high school students from state's public schools who attended school in the mornings were assessed. Thus, other segments that are part of the educational system, such as private, city's public or technical schools and other school hours (afternoon or evening classes) were not assessed. Accordingly, our inferences are related only to the group studied.

The results shown in the present study may serve as the basis for future investigations in areas with specific environmental and social characteristics in the city of São Paulo, providing data for comparisons with both studies 
involving young populations from other regions in Brazil and youths from other countries, and offering important information to assist in creation of intervention strategies or supporting intervention programs that are already being implemented in São Paulo.

In short, the prevalence of physical inactivity among adolescents in São Paulo was high in all geographic areas assessed, and sociodemographic and behavioral factors significantly contributed to physical inactivity.

\section{References}

1. Strong WB, Malina RM, Blimkie CJ, Daniels SR, Dishman RK, Gutin $B$, et al. Evidence based physical activity for school-age youth. J Pediatr. 2005;146:732-7.

2. Parsons TJ, Power $C$, Logan S, Summerbell CD. Childhood predictors of adult obesity: a systematic review. Int J Obes Relat Metab Disord. 1999;23 Suppl 8:S1-107.

3. Tammelin T, Nayha S, Hills AP, Jarvelin MR. Adolescent participation in sports and adult physical activity. Am J Prev Med. 2003;24:22-8.

4. Gordon-Larsen P, Nelson MC, Popkin BM. Longitudinal physical activity and sedentary behavior trends: adolescence to adulthood. Am J Prev Med. 2004;27:277-83.

5. Azevedo MR, Araújo CR, Cozzensa da Silva M, Hallal PC. Tracking of physical activity from adolescence to adulthood: a populationbased study. Rev Saude Publica. 2007;41:69-75.

6. Tammelin T, Ekelund U, Remes J, Nayha S. Physical activity and sedentary behaviors among Finnish youth. Med Sci Sports Exerc. 2007;39:1067-74.

7. Berrigan D, Troiano RP, McNeel T, Disogra C, Ballard-Barbash. Active transportation increases adherence to activity recommendations. Am J Prev Med. 2006;31:210-6.

8. Teixeira e Seabra AF, Maia JA, Mendonça DM, Thomis M, Caspersen $\mathrm{CJ}$, Fulton JE. Age and sex differences in physical activity of Portuguese adolescents. Med Sci Sports Exerc. 2008;40:65-70.

9. Hallal PC, Wells JC, Reichert FF, Anselmi L, Victora CG. Early determinants of physical activity in adolescence: prospective birth cohort study. BMJ.2006;332:1002-6.

10. Ceschini FL, Florindo A, Benício MH. Nível de atividade física em adolescentes de uma região de elevado índice de vulnerabilidade juvenil. Rev Bras Cienc Mov. 2007;15:67-78.

11. Ceschini FL, Figueira Júnior AJ. Prevalência de atividade física insuficiente e fatores associados em adolescentes. Rev Bras Cienc Mov. No prelo 2009.

12. Instituto Brasileiro de Geografia e Estatística (IBGE) [website]. Produto Interno Bruto (PIB) dos Municípios. http://www.ibge. gov.br. Access: 15/10/2008.

13. Associação Nacional de Empresas de Pesquisa (ABEP). Critério de classificação econômica Brasil. São Paulo: Associação Nacional de Empresas de Pesquisa; 2003

14. Matsudo $S$, Araújo T, Matsudo V, Andrade $D$, Andrade E, Oliveira LC, Braggion G. Questionário Internacional de Atividade Física (IPAQ): estudo de validade e reprodutibilidade no Brasil. Rev Bras Ativ Fis Saúde. 2001;6:5-18.
15. Guedes DP, Lopes CC, Guedes JE. Reprodutibilidade e validade do Questionário Internacional de Atividade Física em adolescentes. Rev Bras Med Esporte. 2005;11:151-8.

16. Amorin PR, Faria RC, Byrne NM, Hills AP. Physical activity and nutritional status of Brazilian children of low socieconomic status: undernutrition and overweight. Asia Pac J Clin Nutr. 2006;15:217-23.

17. Brasil.Ministério da Saúde. Questionário de Avaliação das Condições de Saúde, Nutrição e Atividade Física. 2004, portaria n²,246, DOU n² 2, seção 1, p:28-9.

18. Victora CG, Huttly SR, Fuchs SC, Olinto MT. The role of conceptual frameworks in epidemiological analysis: a hierarchical aprroach. Int J Epidemiol. 1997;26:224-7.

19. Riddoch CJ, Bo Andersen, Wedderkopp N, Harro M, KlassonHeggebø L, Sardinha LB, et al. Physical activity levels and patterns of 9-and 15-yr-old European children. Med. Sci. Sports Exerc. 2004;36:86-92.

20. Sindicato Nacional das Empresas de Arquitetura e Engenharia Consultiva. Estudo dos parques paulistanos. 2008. www. nossasaopaulo.org.br/portal/file/estudoparques. Access: $18 / 02 / 2009$.

21. Movimento Nossa São Paulo. Indicadores básicos da cidade de São Paulo. 2009. http://www.nossasaopaulo.org.br/portal/files/ cadernoindicadores2009. Access: 18/02/2009.

22. Van Der Horst K, Paw MC, Twisk JW, Van Mechelen W. A brief review on correlates of physical activity and sedentariness in youth. Med Sci Sports Exerc. 2007;39:1241-50.

23. Farias Júnior JC, Lopes AS. Comportamentos de risco relacionados à saúde em adolescentes. Rev Bras Cienc Mov. 2004;12:7-12.

24. Moreira TC, Belmonte EL, Vieira FL, Noto AR, Ferigolo M, Barros HM. Community violence and alcohol abuse among adolescents: a sex comparison. J Pediatr (Rio J). 2008;84:244-50.

25. Andrade DR, Ceschini FL, Araújo Júnior JF, Matsudo VK. Physical activity level in adolescents from schools with and without Agita Galera Program Intervention. In: International Congress on Physical Activity and Public Health. Atlanta, Georgia. 2006. p:137.

26. Nelson MC, Gordon-Larsen P. Physical activity and sedentary behavior patterns are associated with selected adolescent health risk behaviors. Pediatrics. 2006;117:1281-90.

27. Pate RR, Davis MG, Robinson TN, Stone EJ, McKenzie TL, Young JC, et al. Promoting physical activity in children and youth: a leadership role for schools: a scientific statement from the American Heart Association Council on nutrition, physical activity, and metabolism (physical activity committee) in collaboration with the Councils on Cardiovascular Disease in the Young and Cardiovascular Nursing. Circulation. 2006;114:1214-24.

\section{Correspondence:}

Fabio L. Ceschini

Rua Umberto Boccione, 37

CEP 02441-150 - São Paulo, SP - Brazil

Tel.: +55 (11) 4229.8980

E-mail: flceschini@usp.br 